\title{
Tempromandibular Disorders and Perceived Emotional Stress Among Medical and Dental Students Studying in a Private Medical Institution in Kathmandu, Nepal
}

\author{
Bimb K ${ }^{1}$, Budhthoki $\mathrm{M}^{2}$, Khapung A ${ }^{3}$, Singh $\mathrm{SK}^{4}$ \\ 1,2 Lecturer, Department of Oral and Maxillofacial Surgery, CODS- Nepal Medical College, Kathmandu, Nepal \\ ${ }^{3}$ Lecturer, Department of Community and Preventive Dentistry, CODS-Nepal Medical College, Kathmandu, Nepal \\ ${ }^{4}$ Dental surgeon, Department of Oral and Maxillofacial Surgery, CODS-Nepal Medical College, Kathmandu, Nepal.
}

\begin{abstract}
Introduction: Tempromandibular disorder (TMD) is a collection of complex signs and symptoms that typically involves the tempromandibular joint (TMJ) and masticatory muscles. Multifactorial etiologies of TMD include occlusal disharmony, oral habits, dysfunction of masticatory muscles and adjacent structures, emotional stress and extrinsic and intrinsic changes on TMJ structure. Stress has been inflicted as one of the major etiological factor for developing TMD.

Materials and Methods: An observational cross sectional study was conducted among the medical and dental undergraduate students and interns studying in Nepal Medical College and Teaching Hospital, Kathmandu, Nepal from January 2018 to February 2018. Fonseca Amnestic Index (FAI) was used to evaluate and to characterize the TMD signs and symptoms. The stress factor was assessed by Cohen Perceived Stress Scale (CPSS-10) which is a self report measure of stress level which consist of 10 questionnaires in which the subjects responds on how much they suffer from the listed symptoms. Data was analyzed using the Statistical Package of Social Sciences (SPSS) Version 16.0. Association of different variables were tested, with Chi square test, with value less than 0.05 as statistically significant. Results: A total of 487 students had participated. Among them $32.4 \%$ were male and67.6\%were female. Among the participants, $44.6 \%$ were from dental school (BDS) and 55.4\%were from medical school (MBBS). The age group of the participants was 17 to 27 years. Prevalence of TMD was $50.3 \%$ in the study participants. Among the participants with TMD, $81.2 \%$ had mild TMD, $17.2 \%$ had moderate TMD and 1.6\% had severe TMD. Out of the total participants $16.4 \%$ had low stress, $76.6 \%$ had moderate stress and $7 \%$ had high stress. This study showed statistically significant association between stress factor and tempromandibular disease $(\mathrm{p}<0.001)$.

Conclusion: Higher rate of TMD and level of stress has become common in medical and dental college students. Identifying the TMD at the early age can control or at least minimize its long term effects. Moreover,identifying the stress factor highlights the importance of providing support programs and implementing preventive measures to help students.
\end{abstract}

Key words: Cohen perceived stress scale; Fonseca amnestic index; Stress; Tempromandibular disorders.

Conflict of Interest: No

\section{*Corresponding Author}

Dr. Kushal Bimb

Department of Oral and Maxillofacial Surgery, CODS- Nepal Medical College, Kathmandu, Nepal. E-mail:kushalbimb@gmail.com

\section{Introduction}

Tempromandibular disorder (TMD) is a collection of complex signs and symptoms that typically involves the tempromandibular joint (TMJ) and masticatory muscles. ${ }^{1}$ The presenting features of TMD includes pain in the pre-auricular area, TMJ or masticatory muscles, 
restriction,limitation or deviation in mandibular motions, clicking in the TMJ during mandibular movements and fatigue of the head and neck muscles which are not associated to any growth and development disorders, systemic diseases and trauma. ${ }^{1-5}$ Multifactorial etiologies ofTMD include occlusal disharmony, oral habits, dysfunction of masticatory muscles and adjacent structures, emotional stress and extrinsic and intrinsic changes on TMJ structure. ${ }^{1-5,9-16}$

Studies have shown a high prevalence (60-70\%) of TMD in general populations showing at least one sign of the disorder in a lifetime but only $5 \%$ of them seek for the treatment. ${ }^{1,5}$ Studies among the undergraduate university students have shown $40-70 \%$ prevalence of TMD. ${ }^{4-6}$ Studies in the Indian subcontinent university students have shown a prevalence of $45-65 \%$ of TMD. ${ }^{12,13}$ Study on preclinical dental students of one of the dental colleges in Nepal has shown a prevalence of $38.66 \%{ }^{14}$

Due to variability of complaints, TMD is diagnosed by associating signs and symptoms. Fonseca Amnestic Index (FAI) developed from Helkimo's index, is used to evaluate and to characterize the TMD signs and symptoms in a short period of time, with low cost, easy understanding and having no influence of the evaluator in the answers of the question. ${ }^{1,2,4,6-8}$ Several studies have reported the relationship between TMDs and stress affects parafuctional activities by the limbic system that influences muscle activity. Millan has reported the molecules involved in the mechanism of stress are same associated with the pain resulting in impaired sensation of pain in stressful situations. ${ }^{11}$ De Leuw et al is equivocal that muscle dysfunction and pain are often caused by stress induced muscle hyperactivity. ${ }^{11}$ Cohen's perceived stress scale (CPSS 10) is a brief measure of stress administered via selfreport in which the subjects responds on how much they suffer from the listed symptoms in
Likert scale ranging from 0 (never ) to 4 (very often). Studies have proved the validity and consistency of CPSS as a measure of stress. ${ }^{17-19}$

TMD has been reported with high prevalence in the population with large number of adolescents being affected with it. Stress has been inflicted as one of the major etiological factor for developing TMD. As in case of medical and dental students, high prevalence of stress has been reported. In the management of TMD unless the etiological factors are eliminated there will be little or no improvement with greater chance of recurrence with greater degenerative changes in TMJ. But it is always difficult to eliminate the stress from daily routine. Thus by identifying the TMD at the early age we can control or at least minimize its long term effects. Moreover identifying the stress factor highlights the importance of providing support programs and implementing preventive measures to help students, particularly those who are most susceptible to higher levels of these psychological conditions.

\section{Materials and Methods}

An observational cross sectional study was conducted among the medical and dental undergraduate students and interns studying in Nepal Medical College and Teaching Hospital, Kathmandu, Nepal from January 2018 to June 2019. All the participants were explained about the objective of study and the questionnaires for the study.

Participants previously diagnosed with orofacial pain and undergoing treatment for TMD, participants with any local and/or systemic diseases associated to TMJ or with somatognathic system impairment and those unwilling to participate were not included for the study. Participants who gave written consent were included in the study. Confidentiality of all the participants were maintained

Fonseca Amnestic Index(FAI) (1992) developed from Helkimo'sindex(1974), was used to 
evaluate and to characterize the TMD signs and symptoms. For analysis following values were assigned:10 for yes, 5 for sometimes and 0 for No. The total score gave the Fonseca index classification.Total score for the clinical index was100 with classification as 0-15 (no TMD), 20-40 (mild TMD), 45-65 (moderate TMD) and 70-100 (severe TMD).

The stress factor was assessed by Cohen Perceived Stress Scale (CPSS-10) which is a self report measure of stress level which consist of 10 questionnaires in which the subjects responds on how much they suffer from the listed symptoms in Likert scale ranging from 0 (never) to 4 (very often). The values of the answers were given in the Likert sacale of 0 (never), 1 (almost never), 2 (sometimes), 3 (fairly often) and 4(very often). Total score is 40 with the range of $0-13$ (low stress), 14-26 (moderate stress) and 27-40 (high perceived stress).

Data was analyzed using the Statistical Package of Social Sciences (SPSS) Version 16.0. Association of different variables were tested with Chi square test with value less than 0.05 statistically significant.Ehical cleaarence for this study was approved by Nepal Medical College - Intitution Review Committee (NMCIRC).

Fonseca's Questionnaire for Assessment of TMD

\begin{tabular}{|c|c|c|c|c|}
\hline SN & QUESTIONS & NO & SOMETIMES & YES \\
\hline 1 & Is it hard for you to open your mouth? & & & \\
\hline 2. & Is it hard for you to move yourmandible from side to side? & & & \\
\hline 3. & Do you get tired /muscularpain while chewing? & & & \\
\hline 4. & Do you have frequent headaches? & & & \\
\hline 5. & Do you have pain on the napeor stiff neck? & & & \\
\hline 6. & Do you have earaches or pain intempromandibular joints? & & & \\
\hline 7. & $\begin{array}{l}\text { Have you noticed any TMJ clicking while chewing or } \\
\text { whenyou open your mouth? }\end{array}$ & & & \\
\hline 8. & Do you clench or grindyour teeth? & & & \\
\hline 9. & Do you feel your teeth donot articulate well? & & & \\
\hline 10. & Do you consider yourselfa tense (nervous) person? & & & \\
\hline
\end{tabular}

Questionnaires for Cohen's Perceived Stress Scale (CPSS-10) scoring

\begin{tabular}{|c|c|c|c|c|c|c|}
\hline SN & QUESTIONS & NEVER & $\begin{array}{l}\text { ALMOST } \\
\text { NEVER }\end{array}$ & SOMETIMES & $\begin{array}{l}\text { FAIRLY } \\
\text { OFTEN }\end{array}$ & OFTEN \\
\hline 1. & $\begin{array}{l}\text { In the last month, how often have you } \\
\text { been upset because of something that } \\
\text { happened unexpectedly? }\end{array}$ & & & & & \\
\hline 2. & $\begin{array}{l}\text { In the last month, how often have you } \\
\text { felt unable to control the important } \\
\text { things in your life? }\end{array}$ & & & & & \\
\hline 3. & $\begin{array}{l}\text { In the last month, how often have you } \\
\text { felt nervous or stressed? }\end{array}$ & & & & & \\
\hline 4. & $\begin{array}{l}\text { In the last month, how often have you } \\
\text { felt confident about your ability to } \\
\text { handle personal problems?* }\end{array}$ & & & & & \\
\hline 5. & $\begin{array}{l}\text { In the last month, how often have you } \\
\text { felt that things were going your way? }\end{array}$ & & & & & \\
\hline
\end{tabular}




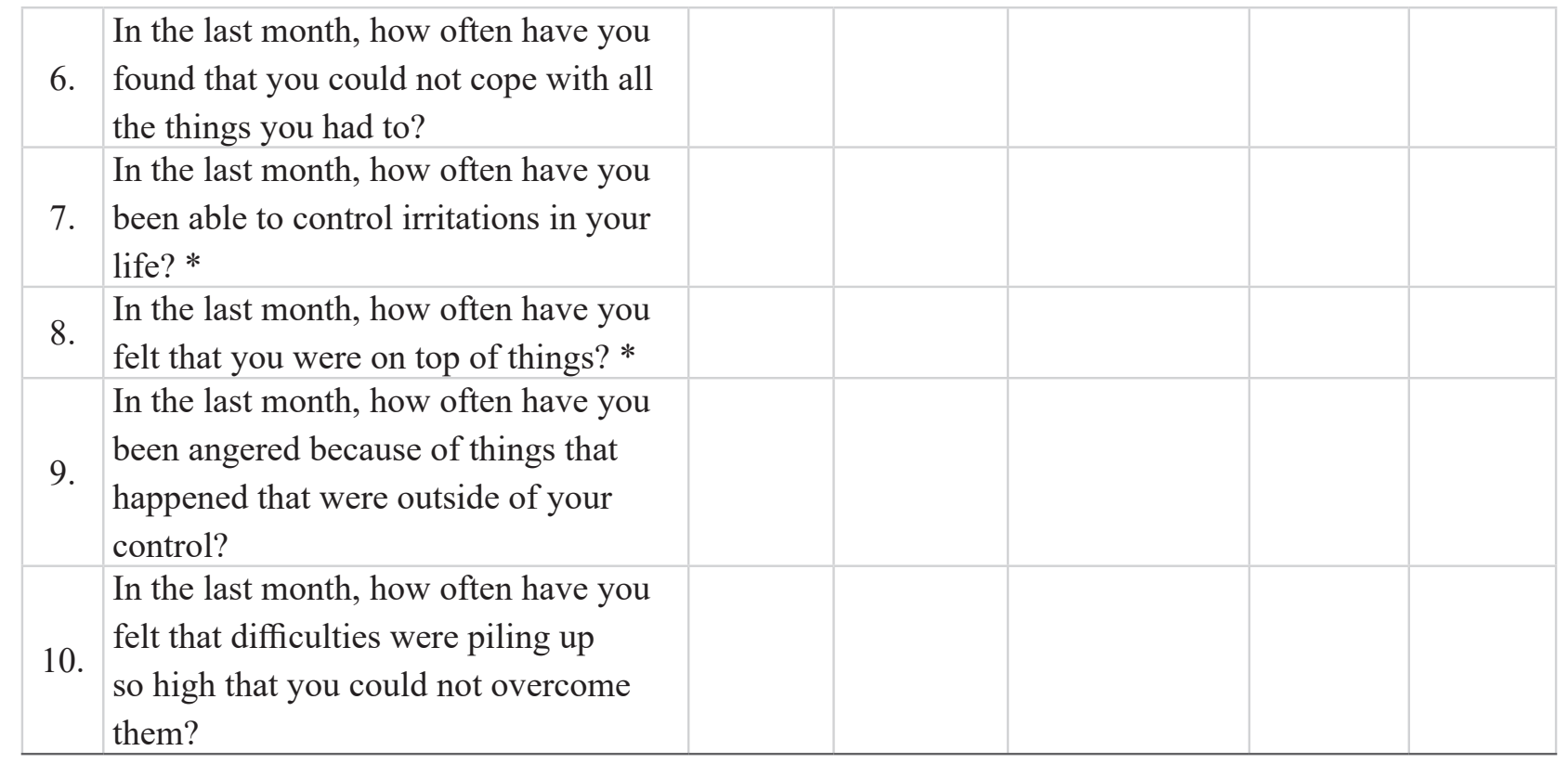

\section{Results}

A total of 487 students had participated. Among them 158 (32.4\%) were male and 329 (67.6\%) were female. Among the participants, 217 students(44.6\%);166 female and 51 male were from dental school(BDS) and 270 students (55.4\%); 163 females and 107 males were from medical school (MBBS). The age group of the participants was 17 to 27 years. Students were from the first year of medical and dental school to the internship.

Out of 487 study participants, 242 participants (110 BDS and 132 MBBS) were graded as having no TMD and 245 having TMD. Prevalence of TMD was $50.3 \%$ among the study participants. Out of the participants with TMD, 199 (81.2\%) had mild TMD, 42 (17.2\%) had moderate TMD and $4(1.6 \%)$ had severe TMD.According to gender, $46.2 \%$ of the males i.e. 73 and $52.3 \%$ of females i.e. 172 had TMD.According to the students' category, $49.3 \%$ of BDS students i.e. 107 and $51.1 \%$ of MBBS students i.e. 138 have TMD. Among 199 students having mild TMD, 94 were BDS students and 105 were MBBS students. Moderate TMD was seen in 42 participants among which 13 were BDS and 29 were MBBS. Severe TMD was seen in just 4 of the MBBS students. These data shows that TMD is slightly more common in female students than male students in both BDS and MBBS category.

Out of the total, 80 participants $(16.4 \%)$ had low stress, $373(76.6 \%)$ had moderate stress and 34 (7\%) had high stress.Low stress level was found in 22 BDS students and 58 MBBS students. Moderate stress level was found in 169 BDS students and 204 MBBS students. High stress level was seen in 26 BDS students and 8 MBBS students.

Association of students of MBBS and BDS and level of TMD was notstatistically significant $(p=0.07)$.

Similarly association of BDS and MBBS students and different level of stress showed statistically significant association between the variables $(\mathrm{p}<0.001)$.

Among 80 participants with low stress level, TMD was present in 26 whereas 54 had no signs of TMD. Those 373 with moderate stress level 195 had TMD and 178 did not have TMD. Similarly, 34 with high stress level, 24 had TMD and 10 did not have any TMD. This study showed statistically significant association between stress factor and tempromandibular disease $(p<0.001)$ 


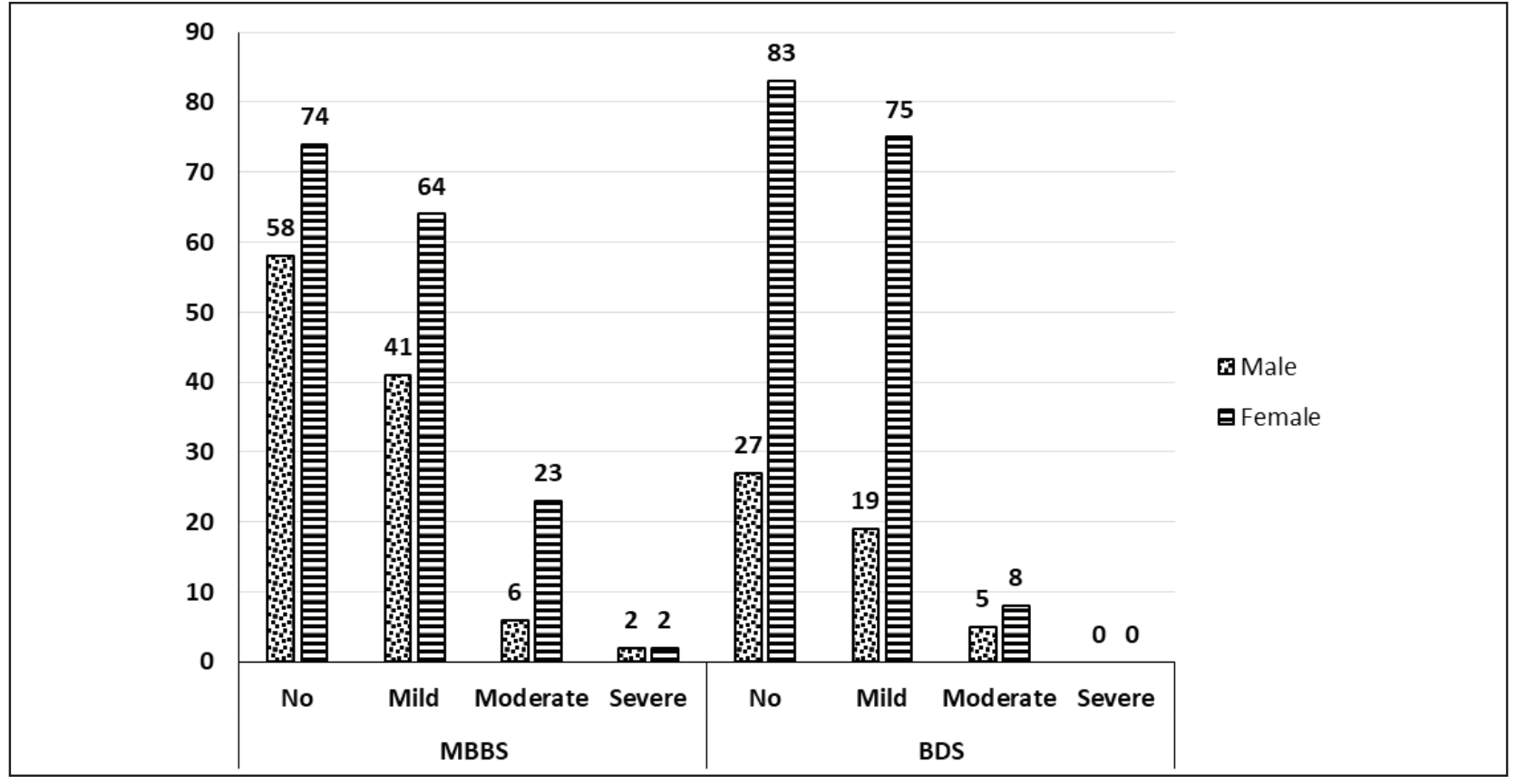

Figure 1: Distribution of study participants according to the level of TMD using Fonseca index

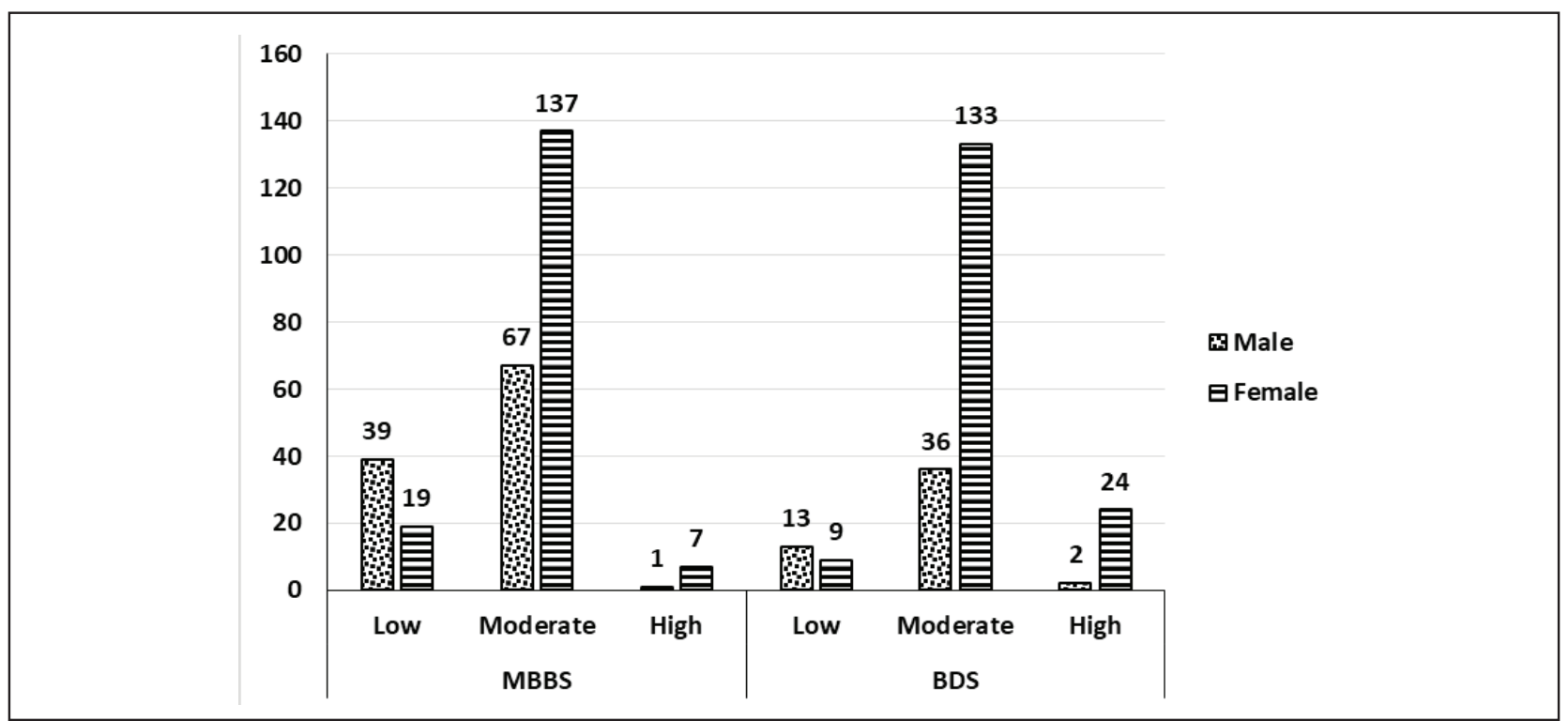

Figure 2: Distribution of study participants according to the degree of stress using CPSS-10

Table 1: Student category and Grading of TMD in Fonseca score cross tabulation

\begin{tabular}{|c|c|c|c|c|c|c|c|}
\hline & \multicolumn{4}{|c|}{ Grading of TMD in Fonseca score } & \multirow[b]{2}{*}{ Total } & \multirow[b]{2}{*}{ p-value } \\
\hline & & No TMD & $\begin{array}{l}\text { MILD } \\
\text { TMD }\end{array}$ & $\begin{array}{c}\text { MODERATE } \\
\text { TMD }\end{array}$ & $\begin{array}{c}\text { SEVERE } \\
\text { TMD }\end{array}$ & & \\
\hline \multirow{2}{*}{ Student of } & BDS & 110 & 94 & 13 & 0 & 217 & 0.07 \\
\hline & MBBS & 132 & 105 & 29 & 4 & 270 & \\
\hline \multicolumn{2}{|c|}{ Total } & 242 & 199 & 42 & 4 & 487 & \\
\hline
\end{tabular}


Table 2: Student category and Grading of Cohen's perceived stresscrosstabulation

\begin{tabular}{|c|c|c|c|c|c|c|}
\hline & \multicolumn{3}{|c|}{ Grading of Cohen's perceived stress } & \multirow[b]{2}{*}{ Total } & \multirow[b]{2}{*}{ p-value } \\
\hline & & $\begin{array}{l}\text { LOW } \\
\text { Stress }\end{array}$ & $\begin{array}{c}\text { MODERATE } \\
\text { Stress }\end{array}$ & $\begin{array}{l}\text { HIGH } \\
\text { Stress }\end{array}$ & & \\
\hline \multirow{2}{*}{ Student of } & BDS & 22 & 169 & 26 & 217 & $<0.001$ \\
\hline & MBBS & 58 & 204 & 8 & 270 & \\
\hline \multicolumn{2}{|c|}{ Total } & 80 & 373 & 34 & 487 & \\
\hline
\end{tabular}

Table 3: Level of stress and TMD cross tabulation

\begin{tabular}{|c|c|c|c|}
\hline Stress factor & TMD present & TMD absent & p-value \\
\hline Low stress & 26 & 54 & $<0.001$ \\
\hline Moderate stress & 195 & 178 & \\
\hline High stress & 24 & 10 & \\
\hline
\end{tabular}

\section{Discussion}

Prevalence of TMD in our study is $50.3 \%$ and is more common in female than male in both BDS and MBBS category. Higher prevalence of TMD (71.9\%) was reported by Augusto in Brazilian under graduate students of health sciences courses, ${ }^{10}$ TMD prevalence of $77.8 \%$ was reported by Ahmed and Abuaffan among medical students of Sudan. ${ }^{15}$ Result similar to this study was shown by Nomuro et al in their study (53.21\%) in Brazilian dental undergraduates and by Bicaj et al (56\%) in Prishtina Dental Sudents using Fonseca Questionnaires. ${ }^{2}$ But Mutlu et al showed less prevalence of $17 \%$ in Turkish dental undergraduate students. ${ }^{3}$ In our study female showed higher prevalence (63.11\%) as compared to males $(40.62 \%)^{1}$ which can be due to higher number of female participants. Majumder et al showed prevalence of TMD in Indian Medical University student to be $31.1 \%$ and Modi et al showed the prevalence of $45.16 \%$ using Fonseca questionnaires in medical and dental undergraduate students with statistically significant difference in the gender. ${ }^{12,13}$ A study by Tiwari et al in medical and dental students in Nepal showed that $38.66 \%$ had remarkable TMD with greater prevalence in male which is in contrast to our study. ${ }^{14}$ In our study $49.3 \%$ of BDS students and $51.1 \%$ of MBBS students have TMD.
Results of present study showed that higher prevalence of moderate stress level in both BDS (77.9\%) and $\operatorname{MBBS}(75.6 \%)$ students. This is significantly more than the study carried by Kharel et al where he studied 375 medical and dental students in Nepal using the Cohen PSS and found the prevalence of stress was $40.34 \%$ in medical students and $34.1 \%$ in dental students ${ }^{19}$.High stress level was found more in BDS students(12\%) than MBBS students (3\%) which is also in contrast to the study by Kharel et al where high stress was more in MBBS students. Moderate and high stress levels were more common for females among both BDS and MBBS students.

This study showed statistically significant relationship between stress factor and tempromandibulardisorder $(\mathrm{p}<0.001)$ which is equivocal with other studies. Harris and Finehave shown a significant relation between TMD and anxiety with $50-75 \%$ of TMD patient have stressful life prior to onset of their symptoms. ${ }^{3}$ Riffel et al have shown a strong correlation between TMD and stress in university students. ${ }^{6}$ Augusto et al have also reported $71.9 \%$ the university students with associated TMD had high scale of perceived stress scale. ${ }^{10}$ Majumder et al has shown that 206 of 300 (66.2\%) medical and dental students with TMD also had signs of anxiety and depression $(\mathrm{p}<0.001){ }^{12}$ 


\section{Conclusion}

Higher rate of TMD and level of stress has become common in medical and dental college students. Academic factors along with other factors like relationship with the peers and faculties, family environment,economical status etc. affect their psychological health which determine their academic performances and physical health. In the management of TMD unless the etiological factors are eliminated there will be little or no improvement with greater chance of recurrence with greater degenerative changes in TMJ. But it is always difficult to eliminate the stress from daily routine. Thus by identifying the TMD at the early age we can control or at least minimize its long term effects. Moreover identifying the stress factor highlights the importance of providing support programs and implementing preventive measures to help students, particularly those who are most susceptible to higher levels of these psychological conditions.

\section{References}

1. Nomura K, Vitti M, Oliveira AS et al. Use of the Fonseca's Questionnaire to assess the prevalence and severity of tempromandibular disorders in Brazilian dental undergraduates. Braz Dent J 2007; 18(2):163-167.

2. Bicaj T, Shala K, Krasniqi TP et al. Frequency of symptoms of tempromandibular disorders among Prishtina Dental Students. Open Access Maced J Med Sci 2017 Oct 15; 5(6):781-784.

3. Mutlu N, Herken H, Guray E et al. Evaluation of the prevalence of tempromandibular joint disorder syndrome in dental school students with psychometric analysis. Turk J Med Sci 2002;32:345-350.

4. Cabral RP, Moiolli- Rodrigues ME, Motta FLK et al. Tempromandibular disorder in university students of the Parque das Rosas Campus, Univesidade Estacio de Sa that practice sports. Health 2016;8:18-23. http://dx.doi.org/10.4236/ health.2016.81003

5. Pesqueira AA, Zulm PRJ, Monteiro DR et al. Relationship between psychological factos and symptoms of TMD in university undergraduate students. Acta OdontoLatinoam 2010;23(3):182-187.

6. RiffelCDT,Flores ME, Scorsatto JT et al. Association of tempromandibular dysfunction and stress in university students. Int $\mathrm{J}$ Odontostomat 2015;9(2):191-197.

7. Campos JADB, Goncalves DAG, Camparis $\mathrm{CM}$ et al. Reliability of a questionnaire for diagnosing the severity of tempromandibular disorder. Rev Bras Fisioter 2009;13(1):38-43.

8. Campos JADB, Carrascosa AC, Bonafe FSS et al. Severity of tempromandibular disorders in women;validity and reliability of the Fonseca Anamnestic Index. Braz Oral Res2014;28(1):1-6. http://dx.doi.org/10.1590/ S1806-83242013005000026

9. Farzaneh B, Salari S, Fekrazad R. Prevalence of tempromandibular joint disorder and stress related dental attrition among army personnel. J Arch Mil Med 2014 Aug;2(3):e20237.http:// dx.doi.org/10.5812/jamm.20137

10. Augusto VG, Perina KCB, Penha DSG et al. Tempromandibular dysfunction, stress and common mental disorder in university students. Acta Ortop Bras 2016;24(6):330-3.http://dx.doi. org/10.1590/1413-785220162406162873

11. Chisnoiu A, Lascu L, Pascu L et al. Emotional stress evaluation in patients with tempromandibular joint disorder. HVM Bioflux 2015;7(2):104-107.

12. Majumder, K., Sharma, S., JK, D.R., Siwach, V., Arya, V. and Gulia, S. Prevalence and sex distribution of temporomandibular disorder and their association with anxiety and depression in Indian medical university students. Int $\mathrm{J} \mathrm{Cln}$ Med2015; 6:570-578.http://dx.doi.org/10.4236/ ijcm.2015.68076

13. Modi P,Shaikh SS, Munde A.A cross sectional study of prevalence of temporomandibular disorders in university students. Int J Sci Res Pub 2012 Sep; 2(9):1-3

14. Tiwari N, Dipesh B, Sushil K. A study on temporomandibular joint disorders among Nepalese preclinical students studying at KMCTH.Indian J Basic Appl Med Res 2017 June; 6(3):549-553.

15. Ahmed LI, Abuaffan AH. Prevalence of temporomandibular joint disorders among 
Sudanese university students. J Oral Hyg Health 20164: 200.doi: 10.4172/2332-0702.1000202

16. BasudanS, BinanzanN, Alhassan A. Depression, anxiety and stress in dental students. Int J Med Ed.2017;8:179-186.ISSN:2042-6372. http:// dx.doi.org/10.5116/ijme.5910.b961

17. Cohen S, Kamark T, Mermelstein. A global measure of perceiced stress. J Health SocialBeh 1983 Dec;24(4):385-396.
18. Cohen S, Williamson GM. Perceived stress in a probablity sample of the United States. The Social Psychology of Health. Newbury Park, CA; Sage, 1988, 31-67

19. Kharel S, Mainalee M, Raut B, Dhungana A, Gupta R. An Evaluation of stress in medical and dental students at Kathmandu Medical College, Nepal. Int Ann Med 2017; 1(5). https:// doi.org/10.24087/IAM.2017.1.7.209 